\title{
Geographic variation in larval cold tolerance and exposure across the invasion front of a widely established forest insect
}

\author{
Running title: Range-wide cold tolerance of an invasive insect
}

Petra Hafker ${ }^{1}$, Lily M. Thompson ${ }^{1,2}$, Jonathan A. Walter ${ }^{1,3}$, Dylan Parry ${ }^{4}$, Kristine L. Grayson ${ }^{1 *}$

${ }^{1}$ Department of Biology, University of Richmond, Richmond, VA

${ }^{2}$ Department of Forestry and Conservation, Clemson University, Clemson, SC

${ }^{3}$ Department of Environmental Sciences, University of Virginia, Charlottesville, VA

${ }^{4}$ Department of Environmental Biology, State University of New York, College of

Environmental Science and Forestry, Syracuse, NY

*Corresponding author:

Kristine Grayson

Department of Biology

University of Richmond

138 UR Drive

Richmond, VA 23173

kgrayson@richmond.edu

Keywords: chill coma recovery, critical thermal limits, forest insect, geographic gradient, Lymantria dispar, spring cold snap, thermal performance

Summary Statement: Chill coma recovery experiments demonstrate geographic variation in cold temperature tolerance for a widespread invasive species, and the risk of early season exposure differs across the invasion front. 


\section{Abstract}

2 As the global climate changes, high and low temperature extremes can drive changes in species

3 distributions. Across the range of a species, thermal tolerance can experience plasticity and may

4 undergo selection, shaping resilience to temperature stress. In this study, we measured variation

5 in the lower thermal tolerance of early instar larvae of an invasive forest insect, Lymantria dispar

6 dispar L. (Lepidoptera: Erebidae), using populations sourced from the climatically diverse

7 invasion of the Eastern United States. In two chill coma recovery experiments, we recorded

8 recovery time following a period of exposure to a non-lethal cold temperature. A third

9 experiment quantified growth responses after chill coma recovery to evaluate sublethal effects.

10 Our results indicate that cold tolerance is linked to regional climate, with individuals from cold

11 climate populations recovering faster from chill coma. While this geographic gradient is seen in

12 many species, detecting this pattern is notable for an introduced species founded from a single

13 point-source introduction. We demonstrate that the cold temperatures used in our experiments

14 occur in nature from cold snaps after spring hatching, but negative impacts to growth and

15 survival appear low. We expect that population differences in cold temperature performance

16 manifest more from differences in temperature-dependent growth than acute exposure.

17 Evaluating intraspecific variation in cold tolerance increases our understanding of the role of

18 climatic gradients on the physiology of an invasive species, and contributes to tools for

19 predicting further expansion. 


\section{Introduction}

Global climate change is driving complex and geographically variable alterations to temperature and microclimate, which in turn can impact population persistence and geographic ranges of organisms. These consequences occur through the impacts of climate change on

24 phenology, growing season length, or the frequency and severity of thermal extremes (Yang et al., 2021). Insects, as short-lived ectotherms, are excellent systems for studying these responses as their physiological performance is sensitive to temperature and their small size allows for experimental studies that might not otherwise be feasible in larger organisms. While research on organismal impacts from climate change often focuses on increasing temperatures, the effects of amplified variability in winter and spring temperatures and the changing frequency of thermal extremes are equally important in the responses of organisms (Cohen et al., 2014; Vavrus et al., 2006). For example, weakening of jet stream air flows or a stratospheric polar vortex can result in unusually extreme cold events when arctic air reaches mid-latitudes (Kretschmer et al., 2018), potentially causing high mortality in overwintering or recently hatched insects (MacQuarrie et

34 al., 2019). Reduced snowfall or earlier snowmelt can reduce insulation and decrease

35 microclimate temperatures for soil-dwelling species or life stages (Lawrence \& Slater, 2010).

36 Shifts in winter conditions and resilience to cold are key drivers of the impacts to insects from

37 climate change (Marshall et al., 2020; Roland \& Matter, 2016; Williams et al., 2015).

Cold stress can cause mortality, as well as sublethal effects on growth and development,

39 for both overwintering insects and larvae at risk of cold snaps after emergence. Many studies

40 have found differences among populations or between closely related species in cold tolerance

41 traits, suggesting the potential for evolutionary responses or plasticity to cold temperatures

42 (Ayrinhac et al., 2004; MacLean et al., 2019). The potential for populations to respond to

43 selective pressure from cold stress is particularly important as species' ranges can shift, expand, 
44 or contract under climate change (Lancaster, 2016; Pureswaran et al., 2018). In these scenarios,

45 insects may experience novel exposure to cold extremes. Invasive species provide a useful

46 surrogate for understanding the evolutionary potential of thermal traits under novel environments

47 in the face of widely changing climate conditions and shifts in species' ranges (Jactel et al.,

48 2019; Kindlmann et al., 2001). Although many invasive species are generalists that can thrive in

49 a wide range of environments, physiological limits to climate tolerance still ultimately shape

50 their potential range (Huey \& Hertz, 1984; Sinclair et al., 2012). Often originating from a single

51 or small number of localized introductions, evolutionary responses during range expansion of

52 invasive species can shed light on the role of plasticity and evolutionary adaptation to extreme

53 temperatures.

54 Several metrics have been used to compare the ability of insects to withstand low

55 temperatures, including cold hardening, chill coma recovery time, and lower critical thermal

56 limits (Sinclair et al., 2015; Sinclair \& Roberts, 2005; Zachariassen, 1985). Chill coma recovery

57 (CCR) is a measure of the time it takes for an individual to regain motor function after being held

58 in low temperature paralysis and returned to an ambient temperature (MacMillan \& Sinclair,

59 2011). This metric has been widely used as a measure of cold tolerance and used in studies

60 examining adaptation to climatic gradients (e.g., Castañeda et al., 2005). Many studies have

61 examined interspecific variation in thermal minimum traits, focusing on macroevolutionary

62 comparisons using insect taxa with species in both tropical and temperate zones to examine the

63 phylogeographic history of cold tolerance traits (David et al., 2003; Gibert \& Huey, 2001;

64 Hoffmann et al., 2002). Examining microevolutionary changes that result in intraspecific

65 variation can provide a window into the potential for adaptive responses of a species to climate

66 change and the development of geographic gradients in thermal traits. Variation in cold tolerance 
67 traits, especially related to CCR, has been most comprehensively studied in and among

68 Drosophila species (e.g., David et al., 1998; Gerken et al., 2016; Gibert et al., 2001; Sisodia \&

69 Singh, 2010). In this study, we use the invasion of a well-known forest insect, Lymantria dispar

70 dispar L. (Lepidoptera: Erebidae; the previous common name, European gypsy moth, is

71 currently under revision) to test for geographic variation in cold tolerance across its invasive

72 range in Eastern North America.

74 from its introduction point near Medford, Massachusetts, USA to inhabit diverse climatic

75 conditions encompassing cold extremes in Minnesota and Eastern Canada to sub-tropical

76 climates at the current southern extreme in North Carolina (Figure 1; Grayson \& Johnson, 2018).

77 Genetic evidence points to a single primary originating population in Massachusetts, which was

78 introduced in 1869 (Wu et al., 2015). Continuous range expansion of $L$. d. dispar over a century

79 allows us to ask questions about the potential for plasticity and evolutionary responses to create

80 intraspecific variation in performance traits among populations, and may inform more broadly,

81 our understanding of trait changes in response to novel climatic environments. Furthermore,

82 invasive species can provide a real-time proxy for the types of temperature shifts facing many

83 other species under anthropogenic climate change.

84 In this study, we measured CCR in 15 populations of $L$. $d$. dispar sourced from the

85 extremes of the United States invasive front as well as from long established areas near the

86 introduction site. We tested whether caterpillar larvae from northern $L$. d. dispar populations are

87 more tolerant of cold temperature stress than those from southern portions of the invasive range

88 by comparing larval CCR among populations for two early instar stages. In addition, we

89 quantified sublethal effects of cold exposure in a post-chill coma growth experiment and 
90 determined the magnitude of cold exposure that each population of larvae experience in their

91 source environment in the spring after hatching. Given previous research suggesting local

92 adaptation has occurred in thermal performance traits and heat tolerance across the L. d. dispar

93 invasive range (Thompson et al., 2017, 2021), we predicted that individuals from northern

94 populations would recover from a chill coma more quickly than those from southern populations.

95 Similarly, we predicted a lag effect on larval growth of $L . d$. dispar after recovery from chill

96 coma, and that this effect would be greater in populations from southern sources than in the

97 north. Investigating intraspecific variation in thermal tolerance will increase our understanding of

98 how these traits can change during the course of an invasion, and whether climate change may

99 alter the success and future spread of this economically and ecologically harmful species in

100 North America.

101

102 Materials and Methods

103 Study system

104 Lymantria dispar dispar L. (Lepidoptera: Erebidae) is a generalist-defoliating forest pest

105 that was introduced to North America in 1869. Populations of this species experience cyclical

106 outbreaks that can cause extensive ecological and economic damage to hardwood forests and

107 disrupt ecosystem processes (Clark et al., 2010; Elkinton \& Liebhold, 1990). The life cycle of $L$.

$108 d$. dispar includes obligate diapause and overwintering as egg masses before hatching in the

109 spring, typically at or near bud break of deciduous trees. The species is a broadly generalist

110 foliage feeder and undergoes five to six larval instars before pupation (Liebhold, 1995). Adult

111 moths are sexually dimorphic, short-lived, and do not feed. Females of this subspecies are

112 flightless and use pheromones to attract flying males for reproduction. Spread of $L . d$. dispar can 
113 be primarily attributed to larval ballooning and human-mediated movement of egg masses

114 attached to objects, vehicles, and firewood (Doane \& McManus, 1981).

115 We used egg masses collected in the field from 15 populations representing five

116 geographic regions in the Eastern United States, including the established invaded range and

117 zones of the invasion front (Figure 1). Egg masses were collected from the field in 2017 or

118 earlier (see Thompson et al., 2021) and successive generations were reared outdoors under

119 identical conditions on oak foliage near Syracuse, NY until shipped to Richmond, VA as egg

120 masses for these experiments (USDA APHIS permits P526P-17-03681(KLG) and P526P-16-

$12104388(\mathrm{DP}))$. For the invasion front regions, four populations were sourced from the extreme

122 northern edge (AL, BF, IR, ELY) and three populations were from the upper Midwest (WI1,

123 WI2, and MN). In the southern portion of the invasion front, three populations came from

124 Appalachia (WV1, WV2, and SWVA) and two populations from the coastal south in North

125 Carolina (NC1 and NC2). From the established invaded range, three populations were sourced

126 from the early invaded range (MA1, MA2, and NY), including two in close geographic

127 proximity to the species' introduction point in Medford, MA (MA1 and MA2). Multiple

128 populations from the five delineated regions were used to account for possible maternal effects

129 from variation between populations in host foliage quality (Erelli \& Elkinton, 2000; Rossiter et

130 al., 1993) and to increase the generality of the results for a given geographic region.

\section{CCR Experiment 1}

We first measured CCR in 2018 using third instar larvae from 14 populations. This initial

134 experiment used $2^{\circ} \mathrm{C}$ for 20 hours as the cold exposure and scored larval recovery time by direct 
135 observation from a single observer. The populations tested and sample sizes are reported in

136 Table 1.

After hatching, larvae were reared in an environmental chamber at $25^{\circ} \mathrm{C}$ (Model

138 DROS33SD, Powers Scientific Inc., Doylestown, PA, USA) and fed a wheat-germ based

139 artificial diet (USDA APHIS Formulation). Upon reaching third instar, larval mass was recorded

140 to the nearest thousandth of a gram and individuals were placed in $30 \mathrm{ml}$ clear, lidded cups

141 without diet. These cups were then transferred into a dark, $2^{\circ} \mathrm{C}$ chamber for 20 hours (Model I-

142 22VL, Percival Scientific, Inc., Perry, Iowa, USA). The temperatures in the chamber and in the

143 lab were recorded every 10 minutes with data loggers to ensure that chilling conditions were

144 maintained throughout the 20-hour period (HOBO U23 Pro v2, Onset Computer Corporation,

145 Bourne, MA, USA). Following the cold exposure, approximately five caterpillars were removed

146 from the chamber at a time, according to staggered chill coma start time, and placed on a lab

147 bench at ambient room temperature. A single observer monitored larval movement at eye-level,

148 six inches from the cups. The time in seconds was recorded for each individual larva to regain

149 motor function (e.g., curling of the head or abdomen, twitching movements, movement of legs or

150 prolegs). The time frame began with entry into the room temperature environment and ended

151 with the first indication of movement. Individuals were included in the analysis if movements

152 were visible in real-time to the naked eye (15 individuals were excluded for failing to meet this

153 criteria, no more than four per population).

155 CCR Experiment 2

156 We conducted a second CCR experiment in 2020, this time using second instar larvae

157 with a cold exposure of $1^{\circ} \mathrm{C}$ for 20 hours to test a colder temperature at a life stage closer to 
158 spring hatching. We had 13 populations available for this experiment (see Table 1 for sample

159 sizes). Larval recovery was observed for up to 54 individuals at a time by two observers and

160 video recordings were used to verify the scored times.

161 After hatching, larvae for this experiment were reared in environmental chambers at $24^{\circ} \mathrm{C}$

162 (Model I-22VL, Percival Scientific, Inc., Perry, Iowa, USA) on the same wheat-germ based diet

163 as in CCR Experiment 1. Given that second instar larvae are very small, mass measurements at

164 the thousandth of a gram did not provide enough precision to detect differences between

165 individuals. Instead, we standardized the developmental point of individuals used in this

166 experiment as two days post-molt.

To reach a colder exposure temperature, we used a benchtop chiller with an antifreeze

168 bath set to $1^{\circ} \mathrm{C}$ (MicroCooler II Model 260010, Boekel Scientific, Feasterville-Trevose, PA,

169 USA). Second instar larvae were placed into microcentrifuge tubes with three or fewer larvae

170 from the same population for 20 hours. An empty vial with a datalogger probe monitored

171 temperature during the trial (EasyLog Data Logger EL-USB-TP-LCD, Lascar Electronics, Erie,

172 PA, USA).

173 After removal from the chiller, larvae were directly placed in labeled petri dishes for each

174 population and recorded using a webcam (Model C910 Logitech HD Pro Webcam, Logitech,

175 Lausanne, Switzerland). One live observer and one virtual observer were present for each trial

176 due to Covid-19 pandemic restrictions in 2020. Recovery time was scored based on observations

177 of first movement, as defined in CCR Experiment 1 (Video S1). Observed movements were

178 verified from the video recording and recovery time was calculated from the time individuals

179 were removed from the chiller and placed in the observation dish. Individuals that crawled into 
180 the lid of the microcentrifuge tube had refuge above the liquid level of the chiller and were

181 excluded (13 individuals were excluded, no more than four per population).

Post-Chill Coma Growth Experiment

We designed an additional experiment to measure the effects on subsequent growth

following a cold exposure resulting in a chill coma. Concurrent with CCR experiment 2 in 2020, second instar larvae from six populations (Table 1) were exposed to a chill temperature or control treatment for 24 hours before being returned to normal diet and rearing temperature.

188 Survival and mass were assessed 10 days post-treatment. Measuring growth over a longer 189 duration was not possible due to Covid-19 pandemic restrictions that limited the number of lab 190 personnel onsite.

Forty larvae were reared from hatch on the same wheat-germ based diet as above in an environmental chamber at $24^{\circ} \mathrm{C}$ (Model I-22VL, Percival Scientific, Inc., Perry, Iowa, USA).

193 Starting size of larvae in the experiment was standardized by using individuals one day following

194 molt. Ten individuals from each population were randomly assigned one of four treatment 195 groups for 24 hours (Figure 2): 1) remain at $24^{\circ} \mathrm{C}$ on diet (control treatment), 2) placed in an 196 empty cup at $24^{\circ} \mathrm{C}$ without diet (a starvation control), 3 ) chilled at $1^{\circ} \mathrm{C}$ (cold exposure without 197 food), 4) chilled at $-2.5^{\circ} \mathrm{C}$ (cold exposure without food). Larvae in the chilled treatments were 198 placed in the same vials and chiller as in CCR experiment 2 . The starvation control at $24^{\circ} \mathrm{C}$ 199 allowed us to separate the effects of the cold exposure treatments from the effect of being 200 removed from food. Following the 24-hour treatment period, individuals were returned to 201 individual containers with diet and the $24^{\circ} \mathrm{C}$ environmental chamber. After ten days, survival 202 was assessed and the mass of each surviving individual was recorded to the nearest thousandth. 
203 Individuals that were dead at 10 days post-treatment (16 out of 240) were excluded from the

204 analysis (Table 1).

205

206

207

208

209

210

211

212

213

214

215

216

217

218

219

220

221

222

223

224

225

Experimental Data Analysis

We examined patterns in CCR across populations relative to the climate of each of the source locations as in Thompson et al. (2021). We examined differences between populations using linear regression with CCR in seconds as the dependent variable and the mean $30-\mathrm{yr}$ climate normal (1981-2010) of the population source location as the independent variable (PRISM Climate Group, Oregon State). With multiple populations represented per region, this approach allowed us to appropriately scale populations based on differences in thermal environments more directly than using a proxy metric such as latitude. For CCR experiment 1, individual mass (g) was included as a covariate while size was standardized in experiment 2 by days post-molt. In the statistical analyses, both climate normal and mass variables were scaled to a mean of zero and standard error of one to account for the difference in magnitude of the values.

In the growth experiment, differences in mass of larvae after exposure to the treatments was analyzed using a two-way ANOVA. The mass (g) of individuals 10 days after treatment exposure was the dependent variable (starting mass was too small to detect differences between individuals at a thousandth of a gram) and the independent variables were the treatment, the population, and their interaction. A post-hoc Tukey Honest Significant Differences test was conducted for the significant independent variables in order to identify the effects that contributed most to differences in mass.

To meet the assumptions of normality, CCR values in CCR experiment 1 were logtransformed. Tansformation of the dependent variable was not necessary for CCR experiment 2 
226 or the growth experiment. Analyses for all experiments were conducted in Program R (version

227 3.6.2; R Core Team, 2019) and significance was evaluated at $\alpha=0.05$.

Site temperatures

Finally, we aimed to contextualize our experiments in terms of cold temperatures experienced by wild populations of $L$. $d$. dispar during larval development. To do this, we quantified the number of days with minimum temperatures below thresholds from the

233 temperatures we used in our experiments $\left(2^{\circ} \mathrm{C},-2.5^{\circ} \mathrm{C}\right)$. Using the locations of the source 234 populations, we quantified the amount of cold each year from the projected median egg hatch 235 date until the end of adult development.

We extracted a daily temperature time series for 2000 to 2020 for the locations of all 15

237 source populations using DAYMET data (Thornton et al., 2020) accessed through the 'daymetr'

238 R package (Hufkens et al., 2018). Median egg hatch date for each year of the temperature time

239 series was projected using the egg development model of the $L$. d. dispar life stage model (GLS;

240 Gray, 2009). The number of days during larval development (as defined by the median egg hatch

241 date +90 days) with minimum temperatures below each threshold was totaled for each year and

242 source population location, then summarized by region.

\section{Results}

\section{CCR Experiment 1}

246 All individuals used in the first CCR experiment survived and regained motor function

247 following chill coma. During the experiment, the environmental chamber had a mean

248 temperature of $2.4^{\circ} \mathrm{C}\left( \pm 0.007^{\circ} \mathrm{C} \mathrm{SE}\right)$ and the ambient room temperature ranged from $22.7^{\circ} \mathrm{C}$ to 
$26.4^{\circ} \mathrm{C}$. Mean population CCR after a 20 -hour exposure to $2^{\circ} \mathrm{C}$ for the third instar larvae ranged

250 from 220 to 1005 seconds. There was a positive relationship between the 30 -year climate normal

251 for a source population location and mean CCR $\left(\operatorname{Adj} . \mathrm{R}^{2}=0.27\right.$, intercept $=5.91$, slope for

252 climate $=0.36, \mathrm{~F}_{(2,322)}=61.7, \mathrm{p}<0.001$; Figure $\left.2 \mathrm{~A}\right)$; populations from warmer climates took

253 longer to recover from chill coma than populations from colder climates.

CCR Experiment 2

All individuals also survived and regained motor function in CCR experiment 2. Two

257 chillers were used and the mean temperature for each chiller across all trials was $1.30^{\circ} \mathrm{C}$ and

$2581.32^{\circ} \mathrm{C}$ with a standard error of $\pm 0.006^{\circ} \mathrm{C}$ and $\pm 0.010^{\circ} \mathrm{C}$, respectively. The ambient temperature

259 was recorded at the start of the CCR period and ranged from $23.7^{\circ} \mathrm{C}$ to $25.2^{\circ} \mathrm{C}$ across all trials.

260 Mean population CCR of second instar larvae ranged from 723 to 1026 seconds following a 20-

261 hour exposure to $1^{\circ} \mathrm{C}$. A weak positive relationship was found between the 30 -year climate

262 normal and mean CCR $\left(\right.$ Adj. $\mathrm{R}^{2}=0.043$, intercept $=733.1$, slope $=12.5, \mathrm{~F}_{(1,354)}=13.5, \mathrm{p}<$

263 0.001; Figure 2B); again, populations from warmer climates tended to take longer to recover

264 from chill coma.

Post-Chill Coma Growth Experiment

The temperatures of the $1^{\circ} \mathrm{C}$ and $-2.5^{\circ} \mathrm{C}$ cold environment chillers were recorded every

268 two minutes yielding mean $( \pm \mathrm{SE})$ temperatures of $1.22 \pm 0.005^{\circ} \mathrm{C}$ and $-2.95 \pm 0.013^{\circ} \mathrm{C}$. Survival

269 ranged from $80 \%$ to $100 \%$ for the 40 larvae in each population and treatment combination (Table

270 1). Occasional morality was seen in all treatments and populations, with slightly lower survival

271 in the Appalachia and Coastal South populations (SWVA and NC2, respectively). 
The interaction of population and treatment did not significantly contribute to the

273 observed differences in growth after chill coma $\left(\mathrm{F}_{(15,200)}=1.4, \mathrm{p}=0.14\right)$. Treatment $\left(24^{\circ} \mathrm{C}\right.$ Diet;

$27424^{\circ} \mathrm{C}$ Starve; $1^{\circ} \mathrm{C}$ Starve; $-2.5^{\circ} \mathrm{C}$ Starve) significantly predicted individual mass 10 days post-

275 treatment $\left(\mathrm{F}_{(3,200)}=27.83, \mathrm{p}<0.001\right)$, with the control treatment $\left(24^{\circ} \mathrm{C}\right.$, Diet $)$ resulting in the

276 largest mass and the coldest treatment $\left(-2.5^{\circ} \mathrm{C}\right.$, Starve) having the smallest mass (Figure 3). All

277 treatments were significantly different from each other (all $\mathrm{p}<0.007)$ based on a pairwise Tukey

278 HSD test except for the $1{ }^{\circ} \mathrm{C}$ Starve treatment and the $24^{\circ} \mathrm{C}$ Starve treatment $(\mathrm{p}=0.96)$.

279 Population was also a significant predictor of individual mass 10 days post-treatment $\left(\mathrm{F}_{(5,200)}=\right.$

$28013.06, \mathrm{p}<0.001)$. Based on a pairwise Tukey HSD test, the WI2 population was significantly

281 different from all other populations $(\mathrm{p}<0.001)$, but the rest of the populations were not

282 significantly different from each other $(\mathrm{p}>0.05$; Figure 3$)$.

Site Temperatures

The 15 population locations in this study are representative of both long-established and

286 recently expanding areas of the $L$. d. dispar range. Between 2000 and 2020, all populations

287 experienced years with at least one day where the minimum temperature was $<2{ }^{\circ} \mathrm{C}$ after

288 predicted larval hatch and during larval development. The southernmost population considered in

289 this study (NC2) was the only location not to experience at least one year with a day where

290 minimum temperature $<-2.5^{\circ} \mathrm{C}$ during predicted larval development (Figure 5, Table S1). The

291 number of days each year with minimum temperatures below $-2.5^{\circ} \mathrm{C}$ during predicted larval

292 development ranged from 0 to 26 for each site and the number of days below $2^{\circ} \mathrm{C}$ ranged from 0

293 to 48 days (Figure 5). Population locations in the Appalachian region experienced the largest 
294 median number of cold days during predicted larval development across years (Figure 5, Table

295 S1).

297 Discussion

This study tested for geographic variation in cold temperature tolerance of an invasive

299 forest insect using CCR experiments. This well-known metric is used for comparative research

300 on cold tolerance and a wide range of studies have used CCR to examine evolutionary and

301 geographic patterns in temperature performance between species or populations (e.g., Klock \&

302 Chown, 2003; MacMillan \& Sinclair, 2011). Our study demonstrates that geographic patterns in

303 CCR can also develop across populations of an invasive species with an expanding range. We

304 found that populations of $L$. d. dispar from colder climates have shorter CCR times than those

305 from warmer climates. We quantified the frequency of early season cold exposure experienced

306 by larval $L . d$. dispar in nature and found that spring cold snaps are common for this species after

307 hatching. Exposure to the chill coma-inducing temperatures used in this study did not impact

308 larval survival, but a single cold exposure did have sublethal effects on growth for larvae chilled

309 to $-2.5^{\circ} \mathrm{C}$ for 24 hours. Exposure to $1^{\circ} \mathrm{C}$ was found to be comparable to larvae removed from

310 food for a similar duration. Under changing climates, resilience to cold temperatures may have

311 important consequences for the development of insect species with early spring hatching

312 phenology.

In our CCR experiments, populations of $L . d$. dispar from warmer climates took longer to

314 recover from exposure to cold temperatures and these geographic differences are consistent with

315 local adaptation of low temperature tolerance traits in colder climates. The potential for

316 intraspecific variation and the genetic basis for CCR response has been demonstrated in several 
317 insect species. Similar studies of variation in CCR of wild-sourced populations of Porcellio

318 laevis (Castañeda et al., 2005) and Eldana saccharina (Kleynhans et al., 2014) also found that

319 populations from warmer locations took longer to recover from chill coma than those from

320 locations with cooler climates. Heritability of cold tolerance has been extensively studied within

321 and among Drosophila species (Morgan \& Mackay, 2006), where artificial selection has

322 demonstrated evolutionary changes in cold-susceptible traits including CCR response (Gerken et

323 al., 2016). While heritability of cold tolerance has not been examined in L. d. dispar, previous

324 work has documented genetic variation between populations (Wu et al., 2015) and spatial genetic

325 structure in development traits (Friedline et al., 2019). Geographic differences in development

326 and growth in response to high temperatures also suggest that local adaptation in thermal traits is

327 occurring in populations across the invasive range (Faske et al., 2019; Thompson et al., 2017).

329 instars and different chill-coma inducing temperatures. New equipment available in 2020

330 allowed testing a colder exposure temperature and we used the opportunity to test both an earlier

331 life stage and more extreme temperature in our second experiment. We found generally shorter

332 recovery times (i.e., higher cold tolerance) for third instar individuals (CCR Experiment 1) than

333 second instar individuals (CCR Experiment 2), but the differences in exposure temperature

334 between the two experiments complicates this comparison. Stage-specific variation has been

335 found in L. d. dispar for tolerance to extreme high temperatures (Banahene et al., 2018).

336 Additional experiments testing the effects of life stage and low temperature exposure in a

337 factorial design would improve our understanding of stage-specific cold tolerance in L. d. dispar.

338 Understanding the cold performance of $L$. d. dispar and the potential for local adaptation

339 in tolerance limits is particularly relevant as this invasive species has begun expanding into 
northern regions with low predicted climate suitability (Gray, 2004). Undoubtedly, winter

341 severity provides the most extreme levels of cold exposure to egg masses and insulation below

342 the snow line has been shown to be a critical factor for survival of overwintering egg masses

343 (Streifel et al., 2019). For larvae, the greatest risks of acute cold exposure come from early spring

344 cold snaps. Using the detailed life stage model available for $L$. $d$. dispar, we were able to

345 quantify the yearly number of days below $2^{\circ} \mathrm{C}$ and $-2.5^{\circ} \mathrm{C}$ after the projected spring hatch and

346 found these temperatures to be common in northern and high elevation locations, and even

347 occasionally occurring in southern populations. Years with cold temperatures after hatching are

348 particularly common for our population locations in Appalachia, the region with the most

349 topographical variation. Here, emergence at high elevation locations was predicted to occur more

350 frequently prior to the end of spring freezing events. The exposure temperatures included in our

351 CCR and growth experiments, while being partly determined by the functional limits of the

352 available equipment, are also biologically relevant to cold temperature stress experienced in

353 nature for the study species.

The cold temperatures used in our experiments caused only minor mortality, which

355 suggests that common spring cold snaps of this magnitude would not result in an appreciable

356 reduction in population size or local extinction. Our growth experiment examined whether acute

357 cold exposure in early instar larvae had persistent effects on growth and development, or whether

358 the exposure was no different than being removed from food for an equivalent time period. The

359 lesser level of cold $\left(1^{\circ} \mathrm{C}\right)$ resulted in growth levels generally similar to starvation at $24^{\circ} \mathrm{C}$, but

360 more extreme cold $\left(-2.5^{\circ} \mathrm{C}\right)$ led to moderately reduced growth during the following 10 days. This

361 effect was seen even after just one instance of cold exposure, and our climate data from the

362 source locations indicates that cold exposure can occur repeatedly in early spring for some years 
363 in colder locations. Contrary to expectations, this response did not differ between populations in

364 the growth experiment. Based on our past work, population variation in L. d. dispar thermal

365 performance during the larval period seems to occur through sublethal effects on temperature-

366 dependent growth rather than acute exposure. Preliminary work indicates that L. d. dispar larvae

367 can survive short cold extremes up to $-8^{\circ} \mathrm{C}$ (KLG unpublished data), well below typical

368 temperatures in a spring cold snap. Similarly, research on L. d. dispar heat stress found tolerance

369 limits well above high temperatures experienced in nature during larval development (Banahene

370 et al., 2018). Thus, sublethal effects of non-optimal, but nonlethal, temperatures can play an

371 important role in the population performance and perhaps, ultimately the realized range of this

372 species. Future work that incorporates longer development times and direct measurement of

373 fitness metrics would improve our knowledge on the constraints and limits of cold temperature

374 exposure on this species.

375 Our work adds to the growing evidence that as an introduced species spreads across a

376 landscape, selection and plasticity in response to novel climates can result in climate-related

377 variation in physiological traits. Exposure to extreme temperatures can be highly variable across

378 heterogeneous landscapes and growing seasons among years. Complex interactions between

379 climate change and phenology can lead to dramatic shifts in local conditions and mismatches that

380 can influence the exposure of insects to spring temperature extremes after hatching or emergence

381 (Forrest, 2016; Pureswaran et al., 2018; Yang et al., 2021). Invasive species with distributions

382 extending into novel climate regions provide an important example of how temperature

383 constraints can shape thermal performance, and ultimately impact population persistence and

384 range limits. 


\section{Acknowledgements}

386 We thank Trevor Faske (University of Nevada, Reno), Chelsea Jahant-Miller (SUNY-ESF),

387 Ksenia Onufrieva (Virginia Tech), Chris Foelker (WI DATP), Kimberly Theilen-Cremers and

388 Natasha Northrop (MN DA), Chris Elder (NC Dept. of Ag and Consumer Services), Jeff

389 Johnson, Scott Hoffman, and CJ Campbell (WV Department of Agriculture), and Valerie

390 Huelsman (Prince William County VA Public Works) for helping us acquire the egg masses that

391 were used in this study. Thanks to Hannah Coovert for helpful comments during the writing

392 process. This study was conducted under USDA APHIS permit numbers P526P-17-03681 and

393 P526P-20-02026 (KLG).

394

\section{Competing Interests}

396 The corresponding author has received funding from the USDA and the Slow-the-Spread

397 Foundation.

398

$399 \quad$ Funding

400 This work was supported by the National Science Foundation under Grant DEB 1702701 under

401 the Macrosystems Biology Program and the Thomas F. and Kate Miller Jeffress Memorial Trust.

402 Additional funding was provided by the Slow-the-Spread Foundation and the University of

403 Richmond School of Arts \& Sciences.

404

405 Data availability

406 Data and code accompanying this study will be publicly archived on Dryad upon manuscript 407 acceptance. 


\section{References}

409

410

Ayrinhac, A., Debat, V., Gibert, P., Kister, A.-G., Legout, H., Moreteau, B., Vergilino, R., \& David, J. R. (2004). Cold adaptation in geographical populations of Drosophila melanogaster: Phenotypic plasticity is more important than genetic variability. Functional Ecology, 18(5), 700-706. https://doi.org/10.1111/j.0269-8463.2004.00904.x

Banahene, N., Salem, S. K., Faske, T. M., Byrne, H. M., Glackin, M., Agosta, S. J., Eckert, A. J., Grayson, K. L., \& Thompson, L. M. (2018). Thermal sensitivity of gypsy moth (Lepidoptera: Erebidae) during larval and pupal development. Environmental Entomology. https://doi.org/10.1093/ee/nvy149

Castañeda, L. E., Lardies, M. A., \& Bozinovic, F. (2005). Interpopulational variation in recovery time from chill coma along a geographic gradient: A study in the common woodlouse, Porcellio laevis. Journal of Insect Physiology, 51(12), 1346-1351. https://doi.org/10.1016/j.jinsphys.2005.08.005

Clark, K. L., Skowronski, N., \& Hom, J. (2010). Invasive insects impact forest carbon dynamics. Global Change Biology, 16(1), 88-101. https://doi.org/10.1111/j.13652486.2009.01983.x

Cohen, J., Screen, J. A., Furtado, J. C., Barlow, M., Whittleston, D., Coumou, D., Francis, J., Dethloff, K., Entekhabi, D., Overland, J., \& Jones, J. (2014). Recent Arctic amplification and extreme mid-latitude weather. Nature Geoscience, 7(9), 627-637. https://doi.org/10.1038/ngeo2234

David, R. J., Gibert, P., Moreteau, B., Gilchrist, G. W., \& Huey, R. B. (2003). The fly that came in from the cold: Geographic variation of recovery time from low-temperature exposure in Drosophila subobscura. Functional Ecology, 17(4), 425-430. https://doi.org/10.1046/j.1365-2435.2003.00750.x 
David, R. J., Gibert, P., Pla, E., Petavy, G., Karan, D., \& Moreteau, B. (1998). Cold stress tolerance in Drosophila: Analysis of chill coma recovery in D. melanogaster. Journal of Thermal Biology, 23(5), 291-299. https://doi.org/10.1016/S0306-4565(98)00020-5

Doane, C. C., \& McManus, M. L. (1981). The Gypsy Moth: Research Toward Integrated Pest Management. U.S. Department of Agriculture.

437 Elkinton, J. S., \& Liebhold, A. M. (1990). Population dynamics of gypsy moth in North America. Annual Review of Entomology, 35(1), 571-596. https://doi.org/10.1146/annurev.en.35.010190.003035

Erelli, M. C., \& Elkinton, J. S. (2000). Maternal effects on gypsy moth (Lepidoptera: Lymantriidae) population dynamics: A field experiment. Environmental Entomology, M., \& Grayson, K. L. (2019). Can gypsy moth stand the heat? A reciprocal transplant experiment with an invasive forest pest across its southern range margin. Biological Invasions, 21(4), 1365-1378. https://doi.org/10.1007/s10530-018-1907-9 in Insect Science, 17, 49-54. https://doi.org/10.1016/j.cois.2016.07.002

Friedline, C. J., Faske, T. M., Lind, B. M., Hobson, E. M., Parry, D., Dyer, R. J., Johnson, D. M., Thompson, L. M., Grayson, K. L., \& Eckert, A. J. (2019). Evolutionary genomics of gypsy moth populations sampled along a latitudinal gradient. Molecular Ecology, 28(9), 2206-2223. https://doi.org/10.1111/mec.15069

Gerken, A. R., Mackay, T. F. C., \& Morgan, T. J. (2016). Artificial selection on chill-coma 
recovery time in Drosophila melanogaster: Direct and correlated responses to selection. Journal of Thermal Biology, 59, 77-85. https://doi.org/10.1016/j.jtherbio.2016.04.004

Gibert, P., \& Huey, R. B. (2001). Chill-coma temperature in Drosophila: Effects of developmental temperature, latitude, and phylogeny. Physiological and Biochemical

Gibert, P., Moreteau, B., Pétavy, G., Karan, D., \& David, J. R. (2001). Chill-coma tolerance, a major climatic adaptation among Drosophila species. Evolution, 55(5), 1063-1068. https://doi.org/10.1111/j.0014-3820.2001.tb00623.x

463

464

465

466

467

468

469

470

471

472

473

474

475

476

477 Zoology, 74(3), 429-434. https://doi.org/10.1086/320429

Gray, D. R. (2009). Age-dependent postdiapause development in the gypsy moth (Lepidoptera: Lymantriidae) life stage model. Environmental Entomology, 38(1), 18-25. https://doi.org/10.1603/022.038.0104

Grayson, K. L., \& Johnson, D. M. (2018). Novel insights on population and range edge dynamics using an unparalleled spatiotemporal record of species invasion. Journal of Animal Ecology, 87(3), 581-593. https://doi.org/10.1111/1365-2656.12755

Hoffmann, A. A., Anderson, A., \& Hallas, R. (2002). Opposing clines for high and low temperature resistance in Drosophila melanogaster. Ecology Letters, 5(5), 614-618. https://doi.org/10.1046/j.1461-0248.2002.00367.x

Huey, R. B., \& Hertz, P. E. (1984). Is a jack-of-all-temperatures a master of none? Evolution, 38(2), 441-444. https://doi.org/10.2307/2408502

Hufkens, K., Basler, D., Milliman, T., Melaas, E. K., \& Richardson, A. D. (2018). An integrated phenology modelling framework in r. Methods in Ecology and Evolution, 9(5), 12761285. https://doi.org/10.1111/2041-210X.12970

Jactel, H., Koricheva, J., \& Castagneyrol, B. (2019). Responses of forest insect pests to climate 
change: Not so simple. Current Opinion in Insect Science, 35, 103-108.

Kindlmann, P., Dixon, A. F. G., \& Dostálková, I. (2001). Role of ageing and temperature in shaping reaction norms and fecundity functions in insects. Journal of Evolutionary

Kleynhans, E., Mitchell, K. A., Conlong, D. E., \& Terblanche, J. S. (2014). Evolved variation in cold tolerance among populations of Eldana saccharina (Lepidoptera: Pyralidae) in South Africa. Journal of Evolutionary Biology, 27(6), 1149-1159. https://doi.org/10.1111/jeb.12390

Klock, C. J., \& Chown, S. L. (2003). Resistance to temperature extremes in sub-Antarctic weevils: Interspecific variation, population differentiation and acclimation. Biological Journal of the Linnean Society, 78(3), 401-414. https://doi.org/10.1046/j.10958312.2003.00154.x

Kretschmer, M., Coumou, D., Agel, L., Barlow, M., Tziperman, E., \& Cohen, J. (2018). Morethermal limits. Nature Climate Change, 6(6), 618-621. https://doi.org/10.1038/nclimate2945 ground climate. Climate Dynamics, 34(7-8), 969-981. https://doi.org/10.1007/s00382009-0537-4 
Liebhold, A. M. (1995). Suitability of North American Tree Species to the Gypsy Moth: A Northeastern Forest Experiment Station.

MacLean, H. J., Sørensen, J. G., Kristensen, T. N., Loeschcke, V., Beedholm, K., Kellermann, V., \& Overgaard, J. (2019). Evolution and plasticity of thermal performance: An analysis Transactions of the Royal Society B: Biological Sciences, 374(1778), 20180548. https://doi.org/10.1098/rstb.2018.0548

MacMillan, H. A., \& Sinclair, B. J. (2011). Mechanisms underlying insect chill-coma. Journal of Insect Physiology, 57(1), 12-20. https://doi.org/10.1016/j.jinsphys.2010.10.004

MacQuarrie, C. J. K., *, Cooke, B. J., \& Saint-Amant, R. (2019). The predicted effect of the polar vortex of 2019 on winter survival of emerald ash borer and mountain pine beetle. Canadian Journal of Forest Research, 49(9), 1165-1172. https://doi.org/10.1139/cjfr-

Marshall, K. E., Gotthard, K., \& Williams, C. M. (2020). Evolutionary impacts of winter climate change on insects. Current Opinion in Insect Science, 41, 54-62.

518 Morgan, T. J., \& Mackay, T. F. C. (2006). Quantitative trait loci for thermotolerance phenotypes in Drosophila melanogaster. Heredity, 96(3), 232-242. https://doi.org/10.1038/sj.hdy.6800786

521 PRISM Climate Group, Oregon State University, 30-Year Normals 1981-2010. https://prism.oregonstate.edu, data created 11 July 2012, accessed 7 Nov 2018.

523 Pureswaran, D. S., Roques, A., \& Battisti, A. (2018). Forest insects and climate change. Current 
Forestry Reports, 4(2), 35-50. https://doi.org/10.1007/s40725-018-0075-6

525 Roland, J., \& Matter, S. F. (2016). Pivotal effect of early-winter temperatures and snowfall on population growth of alpine Parnassius smintheus butterflies. Ecological Monographs,

Rossiter, M. C., Cox-Foster, D. L., \& Briggs, M. A. (1993). Initiation of maternal effects in Lymantria dispar: Genetic and ecological components of egg provisioning. Journal of Evolutionary Biology, 6(4), 577-589. https://doi.org/10.1046/j.1420-

Sharov, A. A., Leonard, D., Liebhold, A. M., Roberts, E. A., \& Dickerson, W. (2002). "Slow the Spread": A national program to contain the gypsy moth. Journal of Forestry, 100(5), 30cold tolerance: Methods, approaches, and workflow. Journal of Thermal Biology, 53, 180-197. https://doi.org/10.1016/j.jtherbio.2015.11.003 among insect populations. Physiological and Biochemical Zoology, 85(6), 594-606.

543 Sisodia, S., \& Singh, B. N. (2010). Influence of developmental temperature on cold shock and chill coma recovery in Drosophila ananassae: Acclimation and latitudinal variations among Indian populations. Journal of Thermal Biology, 35(3), 117-124. 
547 Streifel, M. A., Tobin, P. C., Kees, A. M., \& Aukema, B. H. (2019). Range expansion of

$548 \quad$ Lymantria dispar dispar (L.) (Lepidoptera: Erebidae) along its north-western margin in

549 North America despite low predicted climatic suitability. Journal of Biogeography, 46(1), 58-69. https://doi.org/10.1111/jbi.13474

Thompson, L. M., Faske, T. M., Banahene, N., Grim, D., Agosta, S. J., Parry, D., Tobin, P. C., responses to supraoptimal temperatures near latitudinal range limits of gypsy moth Lymantria dispar (L.), an expanding invasive species. Physiological Entomology, 42(2),

Thompson, L. M., Powers, S. D., Appolon, A., Hafker, P., Milner, L., Parry, D., Agosta, S. J., \& across the invasion front of a widespread non-native insect. Journal of Biogeography,

Thornton, M. M., Shrestha, R., Wei, Y., Thornton, P. E., Kao, S.-C., \& Wilson, B. E. (2020). outbreaks under greenhouse warming. International Journal of Climatology, 26(9), responses of terrestrial organisms to climate change. Biological Reviews, 90(1), 214-235.

569 Wu, Y., Molongoski, J. J., Winograd, D. F., Bogdanowicz, S. M., Louyakis, A. S., Lance, D. R., 
Mastro, V. C., \& Harrison, R. G. (2015). Genetic structure, admixture and invasion success in a Holarctic defoliator, the gypsy moth (Lymantria dispar, Lepidoptera:

573 Yang, L. H., Postema, E. G., Hayes, T. E., Lippey, M. K., \& MacArthur-Waltz, D. J. (2021). The complexity of global change and its effects on insects. Current Opinion in Insect Science, 47, 90-102. https://doi.org/10.1016/j.cois.2021.05.001

576 Zachariassen, K. E. (1985). Physiology of cold tolerance in insects. Physiological Reviews, 


\section{$578 \quad$ Table 1}

579 Population abbreviations, regions, and sample sizes used in the experiments in this study.

\begin{tabular}{|c|c|c|c|c|c|}
\hline \multirow{2}{*}{ Region } & \multirow{2}{*}{ Population } & \multirow{2}{*}{$\begin{array}{l}\text { Elevation } \\
\text { (m asl) }\end{array}$} & \multicolumn{3}{|c|}{ Sample Size } \\
\hline & & & CCR 1 & $C C R 2$ & Growth \\
\hline \multirow{4}{*}{$\begin{array}{c}\text { Northern } \\
\text { Edge }\end{array}$} & ELY & 446 & & 25 & 40 \\
\hline & $\mathrm{BF}$ & 222 & 24 & 32 & 39 \\
\hline & IR & 269 & 21 & 32 & \\
\hline & $\mathrm{AL}$ & 297 & 30 & 17 & \\
\hline \multirow{3}{*}{$\begin{array}{c}\text { Upper } \\
\text { Midwest }\end{array}$} & WI2 & 353 & 22 & 31 & 39 \\
\hline & $\mathrm{MN}$ & 261 & 19 & & \\
\hline & WI1 & 243 & 25 & & \\
\hline \multirow{3}{*}{ Established } & NY & 146 & 18 & 26 & \\
\hline & MA1 & 56 & 23 & 33 & \\
\hline & MA2 & 96 & 21 & 26 & 38 \\
\hline \multirow{3}{*}{ Appalachia } & WV2 & 525 & 20 & & \\
\hline & WV1 & 614 & 19 & 23 & \\
\hline & SWVA & 528 & 20 & 30 & 32 \\
\hline \multirow{2}{*}{$\begin{array}{l}\text { Coastal } \\
\text { South }\end{array}$} & $\mathrm{NC1}$ & 3 & 35 & 45 & \\
\hline & $\mathrm{NC} 2$ & 1 & 28 & 36 & 36 \\
\hline
\end{tabular}

580 Population locations are shown in Figure 1 and coordinates are available in Table S1. The CCR

581 experiments had variable sample sizes due to differences in hatch timing and availability of

582 larvae and the sample sizes reflect the number of individuals in each analysis. The growth

583 experiment was stocked with 40 individuals per population and sample size (n) reflects the

584 number of surviving individuals 10 days post-treatment. 


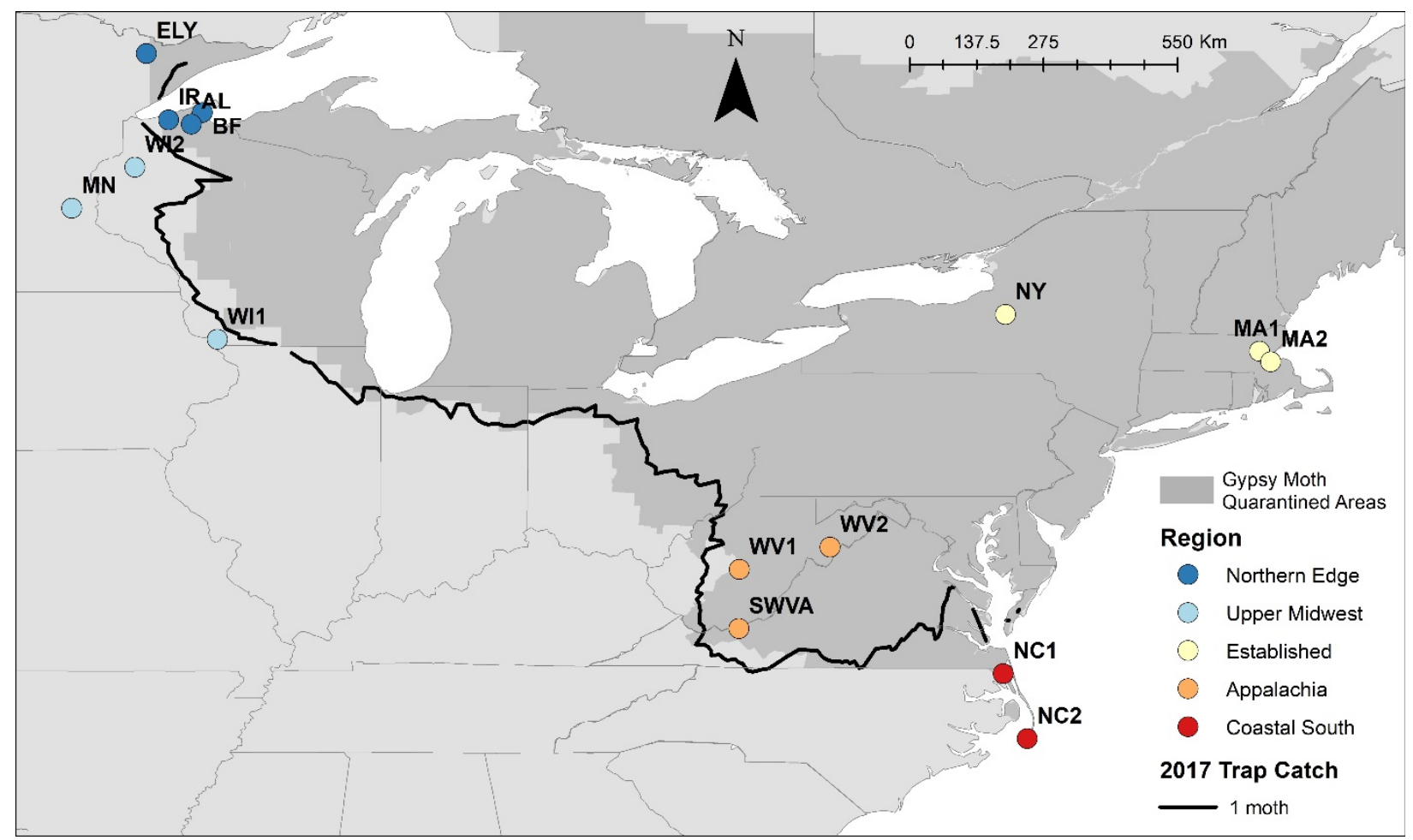

588 Figure 1. Map of Lymantria dispar dispar populations used in this study relative to the

589 invasion front and established range in North America. The established range (darker grey

590 shading) is indicated by counties designated under USDA $L$. d. dispar quarantine regulations.

591 The invasion front shown is the 1-moth trap catch line from the Slow-the-Spread program

592 (Sharov et al., 2002) in 2017. Source populations are colored by the regions defined in this study. 


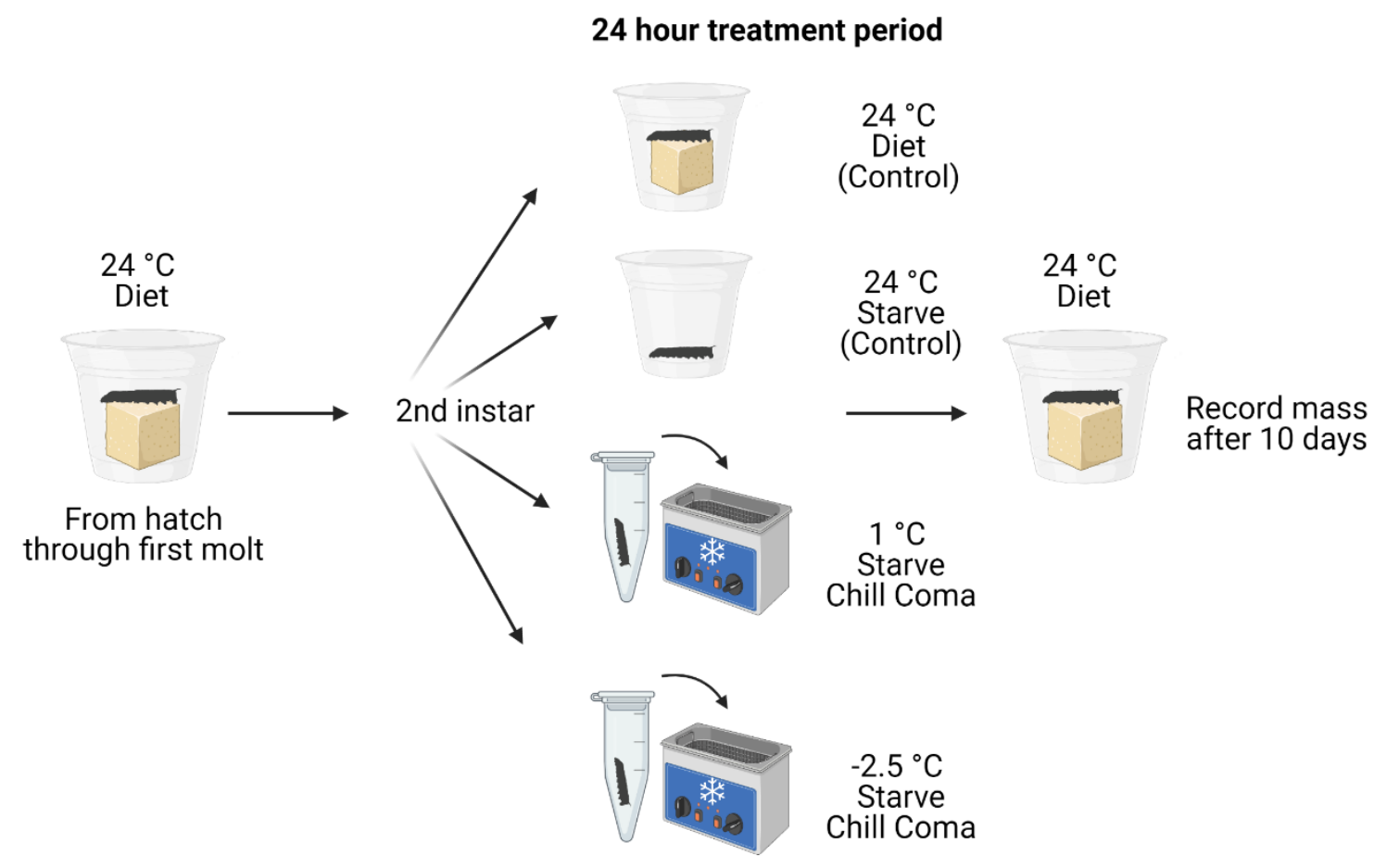

595 Figure 2. Design of the post-CCR growth experiment. All individuals were reared to the

596 second instar on artificial diet before being assigned to one of four treatment groups for 24 hours

$597(\mathrm{~N}=40$ individuals each for six populations). Following exposure to the treatments, all

598 individuals were returned to initial rearing conditions. The mass of each surviving individual was

599 recorded after a 10 day post-treatment growth period. Created with BioRender.com.

600

601 

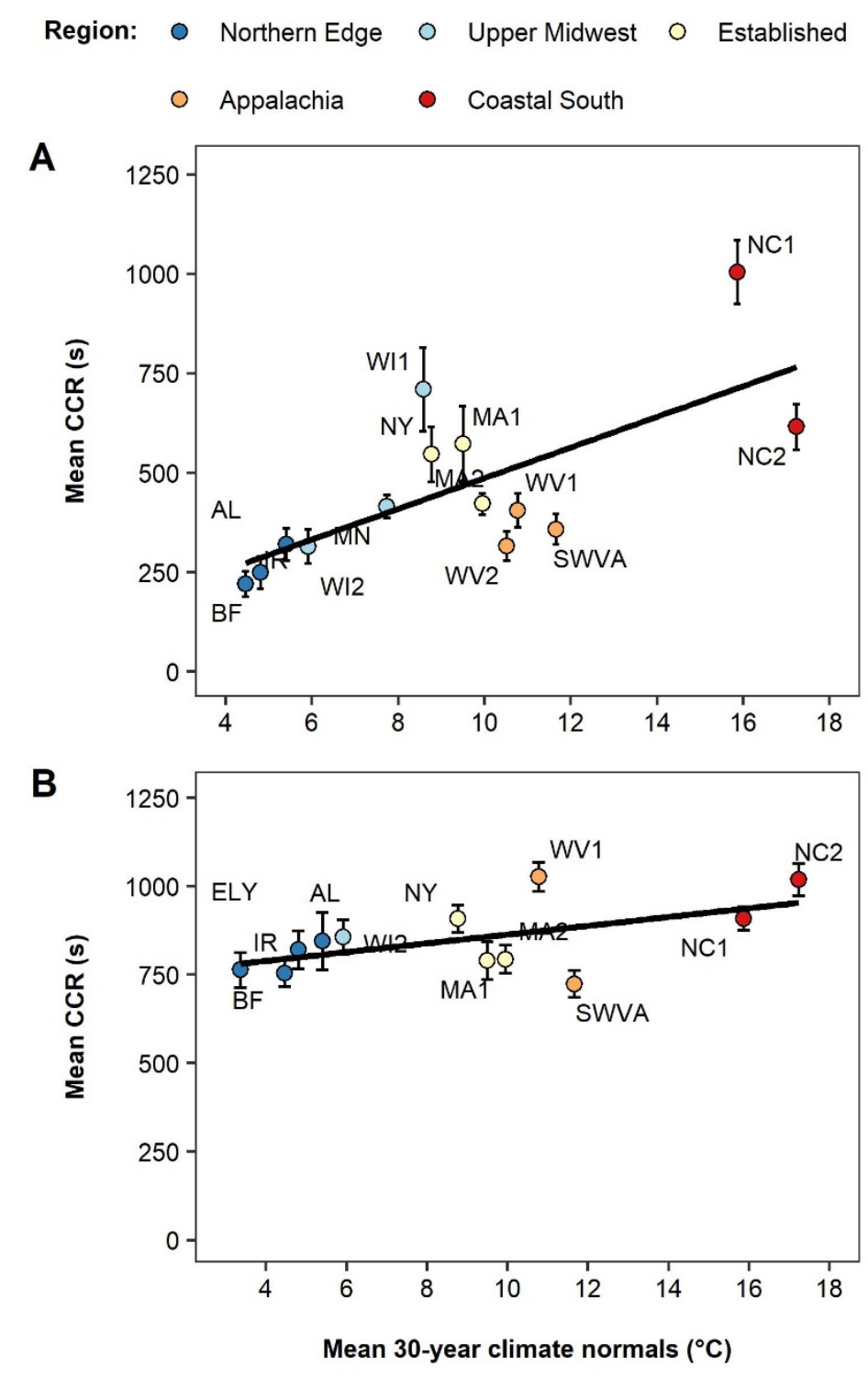

604 Figure 3. The relationship between population climate normals and CCR time for

605 experiments 1 (A) and 2 (B). Experiment 1 tested 3rd instar caterpillar larvae chilled at $2^{\circ} \mathrm{C}$ for

60620 hours. Experiment 2 tested 2 nd instar larvae chilled at $1^{\circ} \mathrm{C}$ for 20 hours. The specific

607 populations used in each experiment and sample sizes are listed in Table 1. 

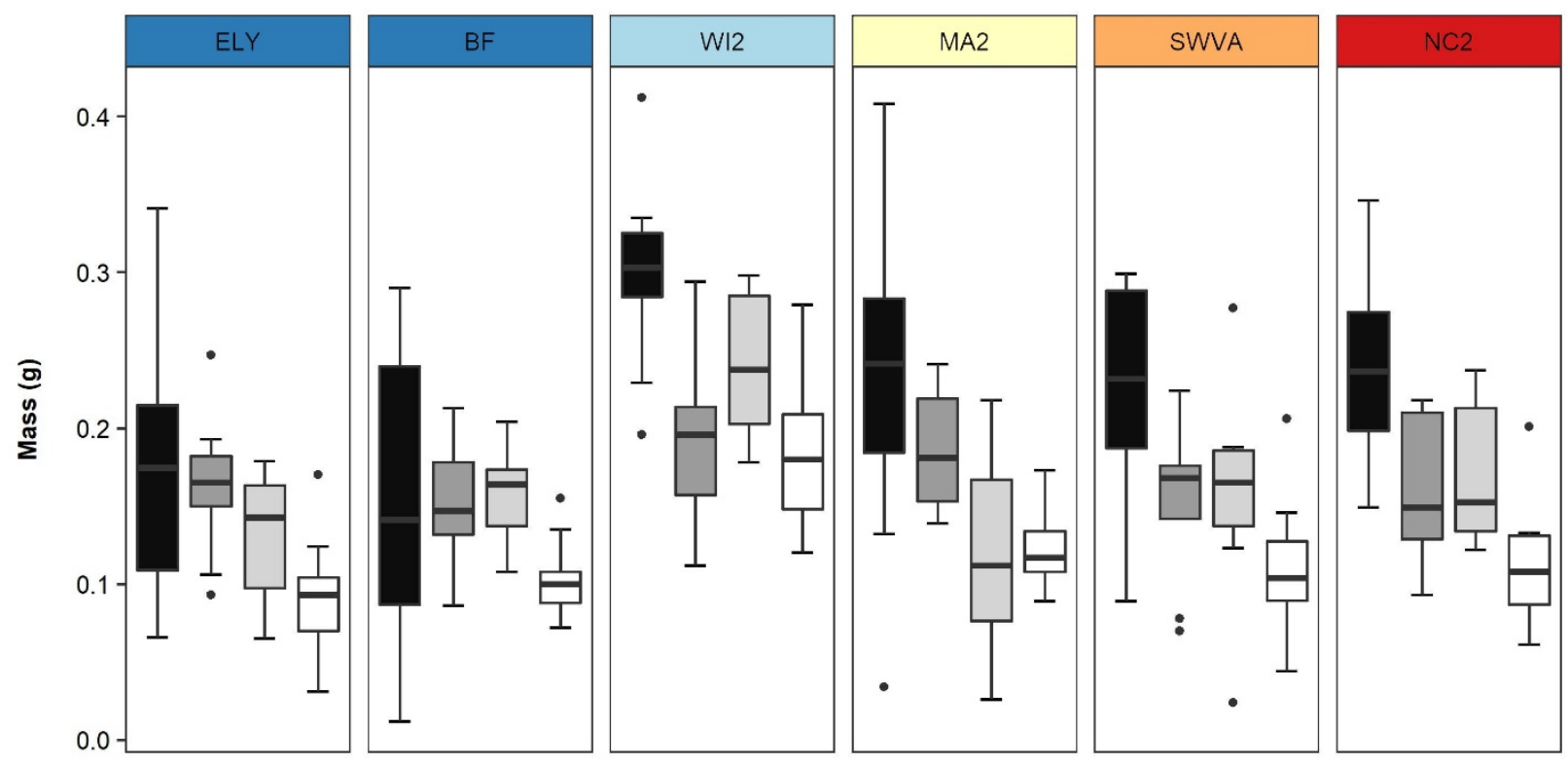

Treatment:

$24^{\circ} \mathrm{C}$, Diet $24^{\circ} \mathrm{C}$, Starve

$1^{\circ} \mathrm{C}$, Starve

$-2.5^{\circ} \mathrm{C}$, Starve

Figure 4. Boxplots of treatment medians per population in the post-chill coma growth

611 experiment. The 24 -hour treatments included two controls at $24^{\circ} \mathrm{C}$ (with artificial diet and

612 starved) and two chilled treatments (at $1^{\circ} \mathrm{C}$ and at $-2.5^{\circ} \mathrm{C}$; illustrated in Figure 2). Mass was

613 measured after 10 days of growth post-exposure to the treatments. Box limits indicate the 25 th

614 and 75th percentiles of the mass data and bars extend 1.5 times the interquartile range from the 25th and 75th percentiles. Outliers are represented by dots. 

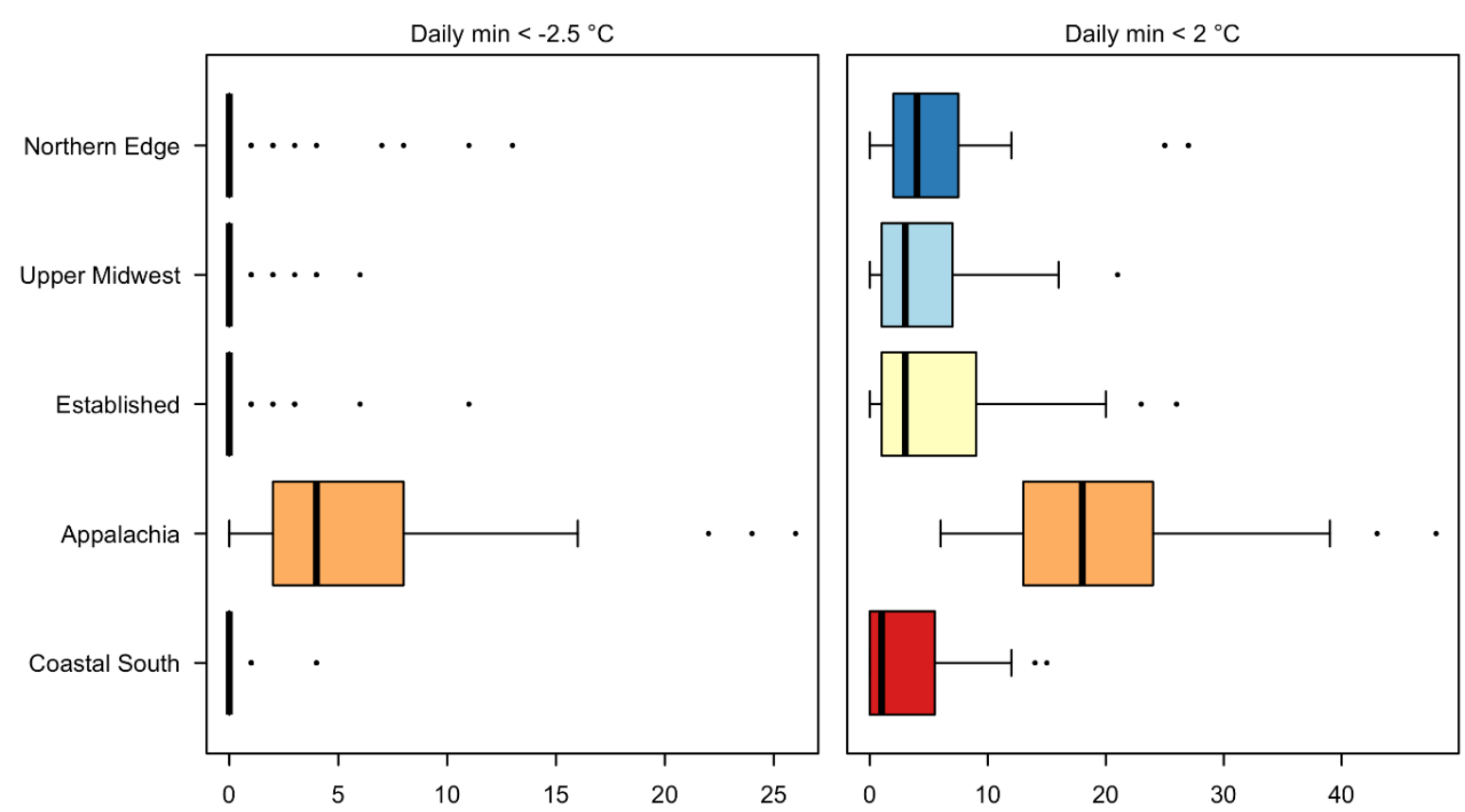

Number of days per year post-hatch

618 Figure 5. Boxplots of the median number of cold days per year (2000 to 2020) during

619 Lymantria dispar dispar larval development by region. Cold days were defined as days with

620 minimum temperatures below $-2.5^{\circ} \mathrm{C}$ and $2^{\circ} \mathrm{C}$ after the projected spring hatch of larvae each

621 year. There are 2 to 4 sites per region corresponding to locations of source populations, and

622 regions are ordered from lowest mean annual temperature to warmest. Box limits indicate the

623 25th and 75 th percentiles of the mass data and bars extend 1.5 times the interquartile range from

624 the 25 th and 75 th percentiles. Outliers are represented by dots. 


\section{Supplementary Information}

\section{Table S1}

627 Population location information and descriptive calculations for number of cold days per 628 year (2000 to 2020) for each location during Lymantria dispar dispar larval development.

\begin{tabular}{|c|c|c|c|c|c|}
\hline \multirow[t]{2}{*}{ Region } & \multirow[t]{2}{*}{ Population } & \multirow[t]{2}{*}{ Location } & \multirow[t]{2}{*}{ Coordinates } & \multicolumn{2}{|c|}{$\begin{array}{c}\text { Mean Days } \pm \text { SD } \\
\text { (Min-Max range days) }\end{array}$} \\
\hline & & & & $<-2.5^{\circ} \mathrm{C}$ & $<2^{\circ} \mathrm{C}$ \\
\hline \multirow{4}{*}{$\begin{array}{l}\text { Northern } \\
\text { Edge }\end{array}$} & ELY & Ely, MN & $\begin{array}{l}47.8991^{\circ} \mathrm{N} \\
91.8584^{\circ} \mathrm{W}\end{array}$ & $0.85 \pm 2.91(0-13)$ & $5.25 \pm 5.89(0-27)$ \\
\hline & $\mathrm{BF}$ & Bayfield, WI & $\begin{array}{l}46.8126^{\circ} \mathrm{N} \\
90.8204^{\circ} \mathrm{W}\end{array}$ & $0.55 \pm 1.82(0-8)$ & $5.40 \pm 5.55(0-25)$ \\
\hline & IR & Iron River, WI & $\begin{array}{l}46.6762^{\circ} \mathrm{N} \\
91.4469^{\circ} \mathrm{W}\end{array}$ & $0.50 \pm 1.61(0-7)$ & $5.40 \pm 5.72(0-25)$ \\
\hline & $\mathrm{AL}$ & Ashland, WI & $\begin{array}{l}46.5967^{\circ} \mathrm{N} \\
91.0251^{\circ} \mathrm{W}\end{array}$ & $1.05 \pm 2.61(0-11)$ & $6.30 \pm 6.33(0-27)$ \\
\hline \multirow{3}{*}{$\begin{array}{l}\text { Upper } \\
\text { Midwest }\end{array}$} & WI2 & Burnett County, WI & $\begin{array}{l}45.8033^{\circ} \mathrm{N} \\
92.0680^{\circ} \mathrm{W}\end{array}$ & $1.02 \pm 1.79(0-6)$ & $6.60 \pm 5.83(0-21)$ \\
\hline & $\mathrm{MN}$ & Minneapolis, MN & $\begin{array}{l}44.8660^{\circ} \mathrm{N} \\
93.2296^{\circ} \mathrm{W}\end{array}$ & $0.15 \pm 0.49(0-2)$ & $3.10 \pm 3.28(0-10)$ \\
\hline & WI1 & Grant County, WI & $\begin{array}{l}42.6231^{\circ} \mathrm{N} \\
90.5451^{\circ} \mathrm{W}\end{array}$ & $0.15 \pm 0.49(0-2)$ & $3.55 \pm 4.02(0-14)$ \\
\hline \multirow{3}{*}{ Established } & NY & Kirkville, NY & $\begin{array}{l}43.0806^{\circ} \mathrm{N} \\
75.9812^{\circ} \mathrm{W}\end{array}$ & $0.85 \pm 2.52(0-11)$ & $6.85 \pm 6.94(0-26)$ \\
\hline & MA1 & Waltham, MA & $\begin{array}{l}42.4050^{\circ} \mathrm{N} \\
71.2871^{\circ} \mathrm{W}\end{array}$ & $0.55 \pm 1.47(0-6)$ & $6.55 \pm 7.06(0-23)$ \\
\hline & MA2 & Randolph, MA & $\begin{array}{l}42.2073^{\circ} \mathrm{N} \\
71.0809^{\circ} \mathrm{W}\end{array}$ & $0.30 \pm 0.80(0-2)$ & $4.70 \pm 5.99(0-19)$ \\
\hline \multirow{3}{*}{ Appalachia } & WV2 & Franklin, WV & $\begin{array}{l}38.7851^{\circ} \mathrm{N} \\
79.2228^{\circ} \mathrm{W}\end{array}$ & $5.40 \pm 6.44(0-26)$ & $19.95 \pm 10.02(6-48)$ \\
\hline & WV1 & Nicholas County, WV & $\begin{array}{l}38.3747^{\circ} \mathrm{N} \\
80.9011^{\circ} \mathrm{W}\end{array}$ & $5.45 \pm 5.67(0-22)$ & $17.50 \pm 9.75(6-43)$ \\
\hline & SWVA & Wolf Creek, VA & $\begin{array}{l}37.2843^{\circ} \mathrm{N} \\
80.9081^{\circ} \mathrm{W}\end{array}$ & $5.80 \pm 5.84(0-24)$ & $20.05 \pm 7.69(8-39)$ \\
\hline \multirow{2}{*}{$\begin{array}{l}\text { Coastal } \\
\text { South }\end{array}$} & $\mathrm{NC} 1$ & Currituck, NC & $\begin{array}{l}36.4491^{\circ} \mathrm{N} \\
76.0246^{\circ} \mathrm{W}\end{array}$ & $0.70 \pm 1.22(0-4)$ & $5.75 \pm 4.52(0-15)$ \\
\hline & $\mathrm{NC} 2$ & Cape Hatteras, NC & $\begin{array}{l}35.2503^{\circ} \mathrm{N} \\
75.5813^{\circ} \mathrm{W}\end{array}$ & $0.00 \pm 0.00(0-0)$ & $0.35 \pm 0.88(0-3)$ \\
\hline
\end{tabular}


629 Cold days were defined as days with minimum temperatures below $-2.5^{\circ} \mathrm{C}$ and $2^{\circ} \mathrm{C}$ after the

630 projected spring hatch of larvae each year. The mean number of days per year \pm standard

631 deviation is shown, with the minimum and maximum number of cold days per year during larval

632 development for 2000 to 2020 shown in parentheses.

\section{Video 1}

635 Example of recovery during 2020 chill coma recovery (CCR) experiment. At timestamp

$63600: 12$, the abdomen of the second instar individual curls signifying recovery from chill coma

637 recovery. Larvae that have not recovered are positioned ventral side up. Movement for the 2020

638 CCR experiment is noted as a twitch, or the curling of the head or abdomen.

639 https://youtu.be/1nuACdMZoUE 